\title{
EFEITO DE DIFERENTES GENÓTIPOS DE SORGO RESISTENTES NO DESEMPENHO DO PULGÃO-VERDE, Schizaphis graminum ROND.
}

\author{
Ivan Cruz ${ }^{1}$ e José D. Vendramim ${ }^{2}$
}

\begin{abstract}
Effect of Different Resistant Sorghum Genotypes on the Performance of the Greenbug, Schizaphis graminum Rond.
\end{abstract}

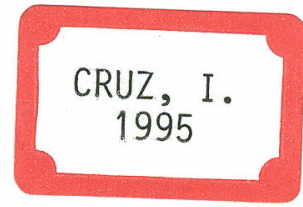

The objective of this work was to evaluate the effect of 28 resistant genotypes of sorghum, Sorghum bicolor (L.) on the biology of the greenbug, Schizaphis graminum Rond., biotype C. The experiments were conducted at the EMBRAPA/CNPMS, in Sete Lagoas, MG. Genotypes were planted in pots and individually infested 11 days after planting, using one newly-born nymph per plant. The evaluation was based on the periods pre-reproductive and reproductive, total life cycle, number of instar, progeny and weight of insects (four and eight days old). The genotypes IS 2293, GR, TX 2567, IS 3422, GSBTX 399 x Capbam, TX 430 x GR, S 9750, $\mathrm{H} 8012$ and GB 3 adversely affected the biology of the insect, increasing the pre-reproductive period and especially decreasing the progeny and the weight of the individuals. Considering the average of these genotypes, the pre-reproductive period of the greenbug was 8.4 days. The average number of offspring was 19.7 nymphs per female and the weight of the insects, 8 days old, was $0.175 \mathrm{mg}$. In comparison to the susceptible check BR 601 an increase of $21.7 \%$ in the reproductive period and a decrease of $51.1 \%$ in the number of offspring and $37.6 \%$ in the insect weight was observed.

KEY WORDS: Insecta, antibiosis, host plant resistance.

\section{RESUMO}

Avaliou-se o efeito de 28 genótipos resistentes de sorgo, Sorghum bicolor (L.) sobre a biologia do pulgão-verde, Schizaphis graminum Rond., biótipo C. Os experimentos foram conduzidos no Centro Nacional de Pesquisa de Milho e Sorgo da EMBRAPA, em Sete Lagoas, MG. Os genótipos foram semeados em vasos e individualmente infestados aos 11 dias de idade com uma ninfa recém-nascida por planta e em seguida, foram cobertos com uma gaiola

Recebido em 25/11/93. Aceito em 05/05/95.

${ }^{1}$ CNPMS/EMBRAPA, Caixa postal 151, 35701-970, Sete Lagoas, MG.

${ }^{2}$ Departamento de Entomologia, ESALQ/USP, Caixa postal 9, 13418-900, Piracicaba, SP. 
cilíndrica. A avaliação foi baseada no número de ínstares, períodos pré-reprodutivo e reprodutivo, ciclo total, número de ninfas produzido e peso dos insetos (quatro e oito dias de idade). Os genótipos IS 2293, GR, TX 2567, IS 3422, GSBTX 399 x Capbam, TX 430 x GR, S 9750, H 8012 e GB 3 afetaram adversamente a biologia do inseto, aumentando o período préreprodutivo e especialmente diminuindo o número de progênies, além de diminuir o peso dos indivíduos. Considerando os valores médios de todos estes genótipos, o período préreprodutivo do pulgão-verde foi de 8,4 dias. O número médio de descendentes foi de 19,7 ninfas por fêmea e o peso dos insetos aos oito dias de vida foi de $0,179 \mathrm{mg}$. Comparativamente à testemunha suscetível BR 601, estes resultados significaram aumento médio de $21,7 \%$ no período pré-reprodutivo e diminuição de $51,1 \%$ no número de descendentes e de $37,6 \%$ no peso dos insetos.

PALAVRAS-CHAVE: Insecta, antibiose, resistência de plantas a insetos.

\section{INTRODUÇÃO}

No Brasil, o pulgão-verde, Schizaphis graminum Rond. foi relatado pela primeira vez, no Rio Grande do Sul, em alpiste e outras gramíneas não cultivadas (Lima 1942). Segundo Gravena (1978), o inseto não tinha sido ainda constatado atacando o sorgo até 1977, mas havia evidentes indícios de que o mesmo se constituiria em sério problema à cultura, provavelmente imigrando das explorações tritícolas do sul do país. Já, Galli et al. (1981) relataram a presença de populações crescentes em sorgo em algumas regiões, indicando que o inseto poderia vir a causar sérios prejuízos uma vez que as condições climáticas brasileiras são favoráveis ao seu desenvolvimento. Segundo Cruz \& Vendramim (1989a), o inseto passa por quatro ínstares, atingindo a maturidade em cerca de uma semana dependendo da temperatura. Reproduz por um período aproximado de 25 dias, produzindo cerca de 44 ninfas por fêmea.

$\mathrm{O}$ pulgão-verde danifica o sorgo extraindo seiva e reduzindo o suprimento de água e nutrientes, injetando na planta substâncias químicas que causam destruição enzimática da parede celular e necrose do tecido foliar, e transmitindo viroses como o mosaico anão do milho (Daniels \& Toler 1969, Berger et al. 1983) ou predispondo a planta a doenças como podridão do colmo (Teetes et al. 1973). Há também um efeito na qualidade do grão, embora poucos trabalhos tenham sido feitos em relação a este tipo de dano (Starks \& Mayo Jr. 1985).

Atualmente já foram identificados oito diferentes raças do inseto (Kerns et al. 1987, 1989). No Brasil considerando a suscetibilidade de vários genótipos e também a resistência de genótipos que são suscetíveis ao biótipo $\mathrm{E}$, confirmados em trabalho de Lopes et al. (1993), utilizando as linhagens de sorgo TX 430, TX 2737 e TX 2783, considera-se que a população predominante no campo seja do biótipo C.

Dentre os métodos estudados para o controle desta praga, a utilização de variedades resistentes tem sido um dos mais importantes. Esta técnica, aliás, tem sido considerada um método ideal para controlar ou diminuir o dano de uma praga a uma cultura (Luginbill 1969, Horber 1972). Em alguns casos, onde se tem plantas altamente resistentes, esse método pode, por si só, ser suficiente para controlar determinada praga (Painter 1958). No Brasil, à semelhança de muitos outros países, as pesquisas visando a obtenção de variedades resistentes, são escassas. Particularmente para a cultura de sorgo, e especificamente para o pulgão-verde, $S$. graminum vale ressaltar entre os poucos trabalhos existentes, aquele de Galli (1979), desenvolvido em Jaboticabal, SP, cuja finalidade foi averiguar a existência de possíveis fontes de resistência e tipos envolvidos, em 47 genótipos de sorgo granífero. Posteriormente, Cruz 
(1986) avaliou cerca de 1000 genótipos, encontrando 28 fontes de resistência ao inseto. Os mecanismos de resistências, bem como os danos provocados tanto em sorgo suscetível quanto resistente têm sido pesquisados (Cruz \& Vendramim, 1988, 1989b).

O objetivo do estudo foi verificar o efeito de diferentes genótipos de sorgo com graus variados de resistência sobre a biologia do pulgão-verde, biótipo $\mathrm{C}$.

\section{MATERIAL E MÉTODOS}

O trabalho foi desenvolvido no Centro Nacional de Pesquisa de Milho e Sorgo da EMBRAPA, em Sete Lagoas, MG. Foram conduzidos experimentos em duas fases. A primeira consistiu em se plantar individualmente em vasos $(20 \mathrm{~cm}$ de maior diâmetroe $25 \mathrm{~cm}$ de altura) com capacidade para $5 \mathrm{~kg}$, com terra previamente adubada, os genótipos a serem estudados. Onze dias após o plantio, realizou-se infestação artificial com ninfas recém-nascidas (uma hora de idade) de $S$. graminum provenientes de criação em sorgo suscetível. Na segunda fase do experimento, utilizou-se ninfas recém-nascidas obtidas dos respectivos genótipos. Assim, na primeira fase utilizaram-se ninfas provenientes de pais criados em genótipos suscetível, enquanto que na segunda fase as ninfas utilizadas originaram-se de pais criados em genótipo resistente, à exceção, da testemunha suscetível. Cada vaso foi coberto com uma gaiola de arame, de forma cilíndrica, ( $20 \mathrm{~cm}$ de diâmetro $\times 40 \mathrm{~cm}$ de altura) envolta por um tecido fino. $O$ delineamento experimental foi inteiramente casualizado com 15 e 10 repetições para a primeira e segunda fase, respectivamente. Foram conduzidos quatro experimentos, sendo avaliados em cada um, sete genótipos com algum grau de resistência ao pulgão-verde (Cruz 1986). Para comparação, foi utilizada em cada experimento, uma testemunha suscetível, o BR 601.

Um experimento foi conduzido à parte para determinar o peso médio dos indivíduos criados nos diferentes genótipos selecionados. Os genótipos foram semeados em vasos, deixando após a emergência, três plantas por genótipo. Onze dias após o plantio, foram efetuadas infestações com ninfas provenientes da criação de manutenção, com idade de uma hora. Quatro dias após a infestação, foram retiradas de cada genótipo, uma amostra contendo 10 ninfas, as quais foram individualmente pesadas. Quatro dias após, uma nova pesagem foi efetuada, a partir de uma amostragem contendo sete indivíduos. O delineamento utilizado foi inteiramente casualizado.

Os dados obtidos, referentes a número de ínstares, período pré-reprodutivo ( nascimento das ninfas até o início da produção dos descendentes), número de ninfas produzido, período reprodutivo, ciclo (período do nascimento até a morte do inseto) e peso dos insetos foram analisados pela ANOVA e comparados usando-se o teste de Duncan $(\mathrm{P}=<0,05)$.

\section{RESULTADOS E DISCUSSÃO}

Experimento 1. Pouca variação ocorreu com número de ínstares de $S$. graminum que foi em média, quatro, em todos os genótipos estudados. O período pré-reprodutivo, compreendido entre o nascimento da ninfa até o aparecimento de suas primeiras progenies, variou de 7,6 a 9,8 dias, na primeira fase e de 6,8 a 9,1 dias, na segunda fase do experimento (Tabela 1). Os insetos criados no sorgo suscetível BR 601, atingiram a maturidade e se reproduziram com uma média de 7,6 e 7,2 dias respectivamente na primeira e segunda fases do experimento. Os genótipos TX 430, IS 3236, TX 2568 propiciaram um desenvolvimento semelhante ao 
Tabela 1. Biologia de Schizaphis graminum em diferentes genótipos de sorgo. Experimento 1 .

\begin{tabular}{lccccc}
\hline Genótipos & \multicolumn{5}{c}{ Parâmetros biológicos $^{1}$} \\
\cline { 2 - 6 } & $\begin{array}{c}\text { Número de } \\
\text { instares }\end{array}$ & $\begin{array}{c}\text { Período } \\
\text { pré-reprod. } \\
\text { (dias) }\end{array}$ & $\begin{array}{c}\text { Número de } \\
\text { ninfas por } \\
\text { fêmea }\end{array}$ & $\begin{array}{c}\text { Período } \\
\text { reprodutivo } \\
\text { (dias) }\end{array}$ & $\begin{array}{c}\text { Ciclo } \\
\text { total } \\
\text { (dias) }\end{array}$ \\
\hline BR 601 & 4,0 & $7,6 \mathrm{~b}$ & $44,2 \mathrm{a}$ & $27,8 \mathrm{a}$ & $50,5 \mathrm{a}$ \\
TX 430 & 4,0 & $8,6 \mathrm{ab}$ & $39,6 \mathrm{ab}$ & $27,5 \mathrm{a}$ & $45,4 \mathrm{ab}$ \\
IS 3236 & 4,0 & $8,3 \mathrm{ab}$ & $38,3 \mathrm{ab}$ & $27,0 \mathrm{a}$ & $47,0 \mathrm{ab}$ \\
TX 2568 & 4,0 & $8,9 \mathrm{ab}$ & $29,0 \mathrm{bc}$ & $26,0 \mathrm{ab}$ & $48,3 \mathrm{ab}$ \\
IS 2293 & 4,0 & $9,0 \mathrm{a}$ & $24,1 \mathrm{~cd}$ & $23,0 \mathrm{ab}$ & $44,5 \mathrm{ab}$ \\
GR & 4,0 & $9,8 \mathrm{a}$ & $18,0 \mathrm{~cd}$ & $23,5 \mathrm{ab}$ & $44,3 \mathrm{ab}$ \\
TX 2567 & 4,0 & $9,5 \mathrm{a}$ & $16,8 \mathrm{~cd}$ & $19,1 \mathrm{bc}$ & $30,3 \mathrm{c}$ \\
IS 3422 & 4,0 & $8,9 \mathrm{ab}$ & $11,9 \mathrm{~d}$ & $14,0 \mathrm{c}$ & $38,0 \mathrm{~b}$ \\
\hline CV (\%) & \multicolumn{5}{c}{31,7} \\
\hline & 16,8 & 28,9 & 27,6 \\
TX 430 & 4,0 & $6,8 \mathrm{c}$ & $56,4 \mathrm{a}$ & 26,5 & 49,0 \\
BR 601 & 4,0 & $7,2 \mathrm{bc}$ & $52,8 \mathrm{a}$ & 26,6 & 43,5 \\
IS 3236 & 4,0 & $7,1 \mathrm{bc}$ & $36,0 \mathrm{~b}$ & 22,5 & 46,8 \\
IS 2293 & 4,0 & $8,7 \mathrm{a}$ & $30,3 \mathrm{~b}$ & 25,5 & 43,1 \\
TX 2568 & 4,0 & $7,6 \mathrm{~b}$ & $29,4 \mathrm{bc}$ & 25,4 & 49,3 \\
GR & 4,0 & $8,9 \mathrm{a}$ & $26,0 \mathrm{bc}$ & 23,2 & 47,0 \\
TX 2567 & 4,0 & $7,1 \mathrm{bc}$ & $21,0 \mathrm{~cd}$ & 22,7 & 47,3 \\
IS 3422 & 4,0 & $9,1 \mathrm{a}$ & $12,3 \mathrm{~d}$ & 19,4 & 37,9 \\
\hline CV (\%) & \multicolumn{5}{c}{24,0} \\
\hline
\end{tabular}

${ }^{1}$ Médias seguidas pela mesma letra na coluna não diferem significativamente, entre si, ao nível de 5\%, segundo o teste de Duncan; ausência de letra na coluna: não significativo pela análise de variância.

${ }^{2}$ Fase 1, pulgões de primeira geração; fase 2, pulgões de segunda geração.

propiciado pelo BR 601 em relação ao período pré-reprodutivo. Os genótipos GR, IS 3422 e IS 2293 foram os que mais afetaram o período pré-reprodutivo do inseto, não diferindo entre si, com média de 9,2 e 8,9 dias, respectivamente na primeira e segunda fases experimental.

O número de ninfas produzido por fêmeas variou de acordo com o genótipo em que os insetos foram criados. As menores progênies foram verificadas para os insetos criados nos genótipos IS 2293, GR, TX 2567 e IS 3422; neste último genótipo, a média do número de ninfas foi 11,9 por fêmea. Na testemunha suscetível (BR 601) foram obtidas 44,2 ninfas. O período reprodutivo e o ciclo total do inseto não variaram entre os genótipos, exceção feita para os insetos criados nos genótipos TX 2567 e IS 3422, que apresentaram médias significativamente menores para os dois parâmetros, em relação à testemunha.

De um modo geral o desempenho dos indivíduos na segunda fase (Tabela 1) foi melhor, 
provavelmente devido a uma melhor adaptação uma vez que foram criados no mesmo hospedeiro dos pais. A média geral para o desenvolvimento do inseto foi 7,8, 24,0 e 45,5 dias para o período pré-reprodutivo, período reprodutivo e ciclo total, respectivamente. O número de ninfas produzido novamente foi menor (12,3 ninfas por fêmea) para os indivíduos criados no genótipo IS 3422, que não diferiu significativamente da média obtida no genótipo TX 2567 (21,0 ninfas por fêmea). Numa posição intermediária ficaram os genótipos IS 3236, IS 2293, TX 2568 e GR, cujo número médio de ninfas produzido foi respectivamente 36,0, 30,3, 29,4 e 26,0 por fêmea. Não houve diferença significativa entre os genótipos com relação ao período reprodutivo e ciclo total, cuja média geral foi respectivamente 24,0 e 45,5 dias.

Experimento 2. Observou-se um alongamento no período pré-reprodutivo dos insetos criados nos genótipos GBSBTX 399 x Capbam e TX 430 x GR, tanto na primeira como na segunda

Tabela 2. Biologia de Schizaphis graminum em diferentes genótipos de sorgo. Experimento 2.

\begin{tabular}{|c|c|c|c|c|c|}
\hline \multirow[b]{2}{*}{ Genótipos } & \multicolumn{5}{|c|}{ Parâmetros Biológicos ${ }^{1}$} \\
\hline & $\begin{array}{l}\text { Número de } \\
\text { ínstares }\end{array}$ & $\begin{array}{l}\text { Período pré- } \\
\text { reprodutivo } \\
\text { (dias) }\end{array}$ & $\begin{array}{c}\text { Número de } \\
\text { ninfas por } \\
\text { fêmea }\end{array}$ & $\begin{array}{l}\text { Período } \\
\text { reprodutivo } \\
\text { (dias) }\end{array}$ & $\begin{array}{l}\text { Ciclo total } \\
\text { (dias) }\end{array}$ \\
\hline & \multicolumn{5}{|c|}{${\text { Fase }{ }^{2}}^{2}$} \\
\hline BR 601 & 4,0 & $7,5 \mathrm{~d}$ & $37,5 \mathrm{a}$ & 26,4 & 54,2 \\
\hline IS $10317 \mathrm{~B}$ & 4,1 & $7,8 \mathrm{~cd}$ & $33,5 \mathrm{ab}$ & 28,1 & 58,2 \\
\hline KS 42 & 4,0 & $7,7 \mathrm{~cd}$ & $29,3 \mathrm{ab}$ & 25,0 & 53,6 \\
\hline E Redlan A & 4,0 & $8,4 \mathrm{~b}$ & $29,0 \mathrm{ab}$ & 27,4 & 65,4 \\
\hline IS $10317 \mathrm{~A}$ & 4,0 & 7,9 bcd & $27,6 \mathrm{~b}$ & 25,4 & 50,3 \\
\hline KS 41 & 4,0 & $8,1 b c$ & $26,8 \mathrm{~b}$ & 26,7 & 67,7 \\
\hline GSBTX 399xCapbam & 4,0 & $9,6 \mathrm{a}$ & $13,0 \mathrm{c}$ & 24,0 & 65,7 \\
\hline TX 430 X GR & 4,0 & $9,2 \mathrm{a}$ & $8,5 \mathrm{c}$ & 11,0 & 36,5 \\
\hline \multirow[t]{2}{*}{ CV (\%) } & & 7,5 & 32,2 & 25,1 & 26,4 \\
\hline & \multicolumn{5}{|c|}{ Fase $2^{2}$} \\
\hline IS $10317 \mathrm{~B}$ & 4,4 & $7,7 \mathrm{~cd}$ & $49,0 \mathrm{a}$ & $30,1 \mathrm{a}$ & 56,4 \\
\hline BR 601 & 4,2 & $7,9 \mathrm{~cd}$ & $48,0 \mathrm{a}$ & $28,8 \mathrm{a}$ & 58,0 \\
\hline IS $10317 \mathrm{~A}$ & 4,2 & $7,1 \mathrm{~d}$ & $43,0 \mathrm{a}$ & $28,4 \mathrm{a}$ & 56,2 \\
\hline KS 42 & 4,3 & $7,6 \mathrm{~cd}$ & $39,3 \mathrm{a}$ & $30,6 \mathrm{a}$ & 62,0 \\
\hline KS 41 & 4,4 & $8,3 b c$ & $25,0 \mathrm{~b}$ & $23,8 \mathrm{ab}$ & 50,3 \\
\hline E Redlan A & 4,0 & $9,1 \mathrm{a}$ & $23,8 \mathrm{~b}$ & $25,5 \mathrm{ab}$ & 54,3 \\
\hline TX $430 \times$ GR & 4,0 & $9,5 \mathrm{a}$ & $17,3 \mathrm{bc}$ & $20,3 \mathrm{~b}$ & 49,3 \\
\hline GSBTX 399xCapbam & 4,1 & $10,0 \mathrm{a}$ & $6,2 \mathrm{c}$ & $8,7 \mathrm{c}$ & 37,3 \\
\hline $\mathrm{CV}(\%)$ & & 11,8 & 31,4 & 25,6 & 29,5 \\
\hline
\end{tabular}

${ }^{1}$ Médias seguidas pela mesma letra na coluna não diferem significativamente, entre si, ao nível de 5\%, segundo o teste de Duncan; ausência de letra na coluna: não significativo pela análise de variância.

${ }^{2}$ Fase 1, pulgões de primeira geração; Fase 2, pulgões de segunda geração. 
fase do experimento (Tabela 2). O número de ninfas produzido por fêmea, na primeira fase, variou de 8,5 a 37,5 por fêmea, dependendo do genótipo em que o inseto foi criado. Não houve diferença significativa para os insetos criados nos genótipos BR 601 ( 37,5 ninfas por fêmea), IS 10317 B (33,5 ninfas por fêmea), KS 42 (29,3 ninfas por fềmea) e E. Redlan A (29,0 ninfas por fêmea). As menores progenies foram obtidas quando os insetos foram criados nos genótipos GBSBTX 399 x Capbam (13,0 ninfas por fêmea) e TX 430 x GR (8,5 ninfas por fêmea). Estas médias foram significativamente diferentes das demais. Uma discriminação bem nítida ocorreu na segunda fase (Tabela 2). Não houve diferença significativa quando os indivíduos foram criados nos genótipos IS 10317 B, BR 601, IS 10317 A e KS 42 cujo número médio de ninfas produzido entre eles foi 44,8 . Uma produção significativamente menor foi obtida para indivíduos criados nos genótipos KS 41, E. Redlan A e TX 430 x GR, não havendo diferença significativa entre as médias de cada um, que foram respectivamente 25,0,23,8 e 17,3 ninfas por fêmea. Finalmente o menor número de ninfas foi produzido pelos indivíduos criados no genótipo GSBTX 399 x Capbam (6,2 ninfas por fêmea).

Experimento 3. Não houve diferença em relação ao período reprodutivo e ciclo total (Tabela 3). Na primeira fase, o período pré-reprodutivo, devido a temperatura média durante o experimento ter sido mais alta em relação aos demais experimentos, foi menor, variando de 6,2 a 7,2 dias, tornando mais difícil a discriminação entre os genótipos. Mesmo assim houve uma tendência a um alongamento do período, para os insetos criados nos genótipos Ranchero, S 9743, Sordan NK, S 9750 e H 8012. Este alongamento ficou mais evidenciado na segunda fase, principalmente para os insetos criados nos genótipos Ranchero e H 8012. No genótipo H 8012 foram também obtidos as menores médias do número de ninfas por fêmea (20,0 e 29,0, respectivamente na primeira e segunda fase experimental).

Experimento 4. Na primeira fase experimental só houve diferença significativa no ciclo total do inseto, sendo menor para os indivíduos criados no genótipo GB 3, cujo período total médio dos indivíduos foi de 32,4 dias, significativamente menor aos valores obtidos pelos indivíduos criados nos demais genótipos (Tabela 4). Não houve diferença significativa para este mesmo parâmetro, na segunda fase do experimento. Houveram diferenças significativas para o período pré-reprodutivo e número de ninfas produzido. Houve uma tendência de alongar o período pré-reprodutivo dos insetos, criados no genótipo GB 3. Também neste genótipo, os indivíduos produziram a menor progênie $(24,7$ ninfas por fêmea), embora não diferindo significativamente da produção obtida quando os insetos foram criados nos genótipos 9-DX19 e 9 DX-73.

$O$ peso das ninfas com quatro dias de idade variou de 0,070 a 0,176 miligramas (Tabela 5 ), sendo que os maiores pesos foram obtidos quando os insetos foram alimentados nos genótipos CMSXS 309 (0,176 mg) e BR 007, (0,162 mg), uma linhagem muito suscetível ao inseto. Os menores pesos foram observados para os indivíduos criados nos genótipos IS 2293 e 9 DX 19, com 0,070 e 0,071 mg, respectivamente; não houve diferença significativa entre indivíduos apresentando pesos médios variando de 0,070 a $0,103 \mathrm{mg}$. Dentro desse grupo se enquadram genótipos considerados bem resistentes como o TX 430 x GR, e Relan A, GSBTX 399 x Capbam, TX 2567, H 8012, GB 3, KS 42 e Ranchero (Cruz 1986). A situação permaneceu inalterada na pesagem realizada, quando os indivíduos estavam com oito dias de idade $(0,153$ a $0,287 \mathrm{mg})$. 
Tabela 3. Biologia de Schizaphis graminum em diferentes genótipos de sorgo. Experimento 3.

\begin{tabular}{|c|c|c|c|c|c|}
\hline \multirow[b]{2}{*}{ Genótipos } & \multicolumn{5}{|c|}{ Parâmetros Biológicos ${ }^{1}$} \\
\hline & $\begin{array}{l}\text { Número de } \\
\text { ínstares }\end{array}$ & $\begin{array}{l}\text { Período pré- } \\
\text { reprodutivo } \\
\text { (dias) }\end{array}$ & $\begin{array}{l}\text { Número de } \\
\text { ninfas por } \\
\text { fềmea }\end{array}$ & $\begin{array}{l}\text { Período } \\
\text { reprodutivo } \\
\text { (dias) }\end{array}$ & $\begin{array}{l}\text { Ciclo total } \\
\text { (dias) }\end{array}$ \\
\hline \multicolumn{6}{|c|}{ Fase $1^{2}$} \\
\hline CMS X S 309 & 4,0 & $6,4 \mathrm{~cd}$ & $45,6 \mathrm{a}$ & 21,3 & 35,3 a \\
\hline Ranchero & 4,0 & $6,8 \mathrm{abc}$ & $43,2 \mathrm{ab}$ & 23,8 & $35,1 \mathrm{a}$ \\
\hline Pioneer 8199 & 4,1 & $6,2 \mathrm{~d}$ & $40,8 \mathrm{abc}$ & 21,0 & $31,6 \mathrm{ab}$ \\
\hline BR 601 & 4,0 & $6,5 \mathrm{bcd}$ & $40,6 \mathrm{abc}$ & 21,5 & $32,4 a b$ \\
\hline S 9743 & 4,0 & $7,0 a b c$ & $31,6 \mathrm{bcd}$ & 17,5 & $26,0 \mathrm{~b}$ \\
\hline Sordan NK & 4,0 & $7,1 \mathrm{ab}$ & 31,4 bcd & 20,5 & $34,9 a b$ \\
\hline S 9750 & 4,0 & 7,2 a & $28,6 \mathrm{~cd}$ & 21,1 & $32,6 a b$ \\
\hline H 8012 & 4,0 & $7,1 \mathrm{ab}$ & $20,0 \mathrm{~d}$ & 13,8 & $25,2 \mathrm{~b}$ \\
\hline CV (\%) & & 9,1 & 19,6 & 10,7 & 13,1 \\
\hline \multicolumn{6}{|c|}{ Fase $2^{2}$} \\
\hline Pioneer 8199 & 4,0 & $6,0 \mathrm{c}$ & 46,3 a & 24,5 & 35,0 \\
\hline CMS X S 309 & 4,0 & $6,3 \mathrm{bc}$ & $43,4 a$ & 23,8 & 34,6 \\
\hline BR 601 & 4,0 & $6,0 \mathrm{c}$ & $43,2 \mathrm{a}$ & 23,8 & 38,2 \\
\hline Ranchero & 4,0 & $6,8 \mathrm{ab}$ & $40,8 \mathrm{ab}$ & 24,0 & 36,1 \\
\hline NK Sordan & 4,0 & $6,6 b c$ & $40,0 \mathrm{ab}$ & 25,7 & 39,5 \\
\hline S 9743 & 4,0 & $6,4 b c$ & $36,5 a b c$ & 25,3 & 34,5 \\
\hline S 9750 & 4,2 & $6,0 \mathrm{c}$ & $32,2 \mathrm{c}$ & 21,7 & 30,7 \\
\hline H 8012 & 4,0 & $7,3 \mathrm{a}$ & $29,0 \mathrm{c}$ & 21,7 & 34,5 \\
\hline CV (\%) & & 9,5 & 34,2 & 30,4 & 23,3 \\
\hline
\end{tabular}

${ }^{1}$ Médias seguidas pela mesma letra na coluna não diferem significativamente, entre si, ao nível de 5\% segundo o teste de Duncan; ausência de letra na coluna: não significativo pela análise de variância.

${ }^{2}$ Fase 1, pulgões de primeira geração; Fase 2, pulgões de segunda geração.

Dos genótipos avaliados, TX 430, 9 DX 6-27-1 e Ruby apresentaram a tolerância como o principal mecanismo de resistência ao $S$. graminum e TX 430 x GR, GR, GSBTX 399 x Capbam, S 9743, H 8012, GB 3 e S 9750 apresentaram a não-preferência como mecanismo principal de resistência (Cruz 1986, Cruz \& Vendramim 1989b). É provável que antibiose seja o principal mecanismo de resistência nos genótipos IS 2293 e KS 41. Antibiose juntamente com não-preferência provavelmente estejam presentes nos genótipos S 9750, H 8012, GSBTX 399 x Capbam e Redlan A, 9DX-19, IS 3236 e IS 3422. Finalmente considerando os resultados 
desse e de experimentos anteriores, é possível que os três mecanismos de resistência sejam encontrados nos genótipos TX 430 x GR, GB 3 e TX 2567 (Cruz 1986).

Conclui-se que embora haja um ou mais mecanismos de resistência envolvidos em um ou mais genótipos avaliados em relação ao pulgão-verde, S. graminum, os genótipos IS 2293, GR, TX 2567, IS 3422 GSBTX 399 x Capbam, TX 430 x GR, S 9750, H 8012 e GB 3 afetaram adversamente a biologia do inseto, com tendência a aumentar o seu período pré-reprodutivo

Tabela 4. Biologia de Schizaphis graminum em diferentes genótipos de sorgo. Experimento 4.

\begin{tabular}{|c|c|c|c|c|c|}
\hline \multirow[b]{2}{*}{ Genótipos } & \multicolumn{5}{|c|}{ Parâmetros Biológicos ${ }^{1}$} \\
\hline & $\begin{array}{l}\text { Número de } \\
\text { ínstares }\end{array}$ & $\begin{array}{l}\text { Período pré- } \\
\text { reprodutivo } \\
\text { (dias) }\end{array}$ & $\begin{array}{l}\text { Número de } \\
\text { ninfas por } \\
\text { fêmea }\end{array}$ & $\begin{array}{l}\text { Período } \\
\text { reprodutivo } \\
\text { (dias) }\end{array}$ & $\begin{array}{l}\text { Ciclo total } \\
\text { (dias) }\end{array}$ \\
\hline \multicolumn{6}{|c|}{ Fase $1^{2}$} \\
\hline Ruby & 4,1 & 6,0 & 56,4 & 22,4 & $37,5 \mathrm{ab}$ \\
\hline OK $8 \mathrm{~B}$ & 4,0 & 6,4 & 52,2 & 22,0 & $40,9 \mathrm{ab}$ \\
\hline BR 601 & 4,0 & 6,3 & 48,9 & 24,2 & $42,4 \mathrm{ab}$ \\
\hline 9 DX 73 & 4,0 & 6,3 & 45,6 & 23,0 & $42,5 \mathrm{a}$ \\
\hline 9 DX 6271 & 4,0 & 6,1 & 42,4 & 22,9 & $38,8 \mathrm{ab}$ \\
\hline 9 DX 19 & 4,0 & 6,1 & 38,3 & 21,1 & $37,5 \mathrm{ab}$ \\
\hline KS 9 B & 4,0 & 6,1 & 36,4 & 21,5 & $37,4 \mathrm{~b}$ \\
\hline GB 3 & 4,0 & 6,6 & 34,0 & 20,9 & $32,4 \mathrm{c}$ \\
\hline $\mathrm{CV}(\%)$ & & 9,9 & 25,1 & 20,8 & 15,0 \\
\hline \multicolumn{6}{|c|}{ Fase $2^{2}$} \\
\hline Ruby & 4,0 & $5,3 \mathrm{~d}$ & $46,5 \mathrm{a}$ & 22,9 & 43,4 \\
\hline OK $8 \mathrm{~B}$ & 4,0 & $5,4 \mathrm{~cd}$ & $42,9 \mathrm{a}$ & 21,9 & 45,3 \\
\hline BR 601 & 4,0 & $6,4 a b$ & $35,8 \mathrm{~b}$ & 21,4 & 38,9 \\
\hline 9 DX 6271 & 4,0 & $5,7 \mathrm{~cd}$ & $32,7 \mathrm{bc}$ & 20,3 & 40,9 \\
\hline KS 9 B & 4,0 & $6,3 \mathrm{ab}$ & $32,5 \mathrm{bc}$ & 21,4 & 44,2 \\
\hline 9 DX 73 & 4,0 & $5,9 \mathrm{bcd}$ & $26,8 \mathrm{~cd}$ & 21,8 & 41,5 \\
\hline 9 DX 19 & 4,0 & $6,0 \mathrm{bc}$ & $25,6 \mathrm{~cd}$ & 21,3 & 39,1 \\
\hline GB 3 & 4,0 & $6,7 \mathrm{a}$ & $24,7 d$ & 19,9 & 39,9 \\
\hline CV $(\%)$ & & 10,1 & 20,5 & 11,6 & 15,2 \\
\hline
\end{tabular}

${ }^{1}$ Médias seguidas pela mesma letra na coluna não diferem significativamente, entre si, ao nível de 5\% segundo o teste de Duncan; ausência de letra na coluna: não significativo pela análise de variância.

${ }^{2}$ Fase 1, pulgões de primeira geração; Fase 2, pulgões de segunda geração. 
e especialmente diminuir o número de descendentes, além de diminuir o peso dos indivíduos. Considerando os valores médios de todos estes genótipos, o período pré-reprodutivo do pulgão-verde foi de 8,4 dias, o número médio de descendentes foi de 19,7 ninfas por fêmea e o peso dos insetos aos oito dias de vida foi de $0,179 \mathrm{mg}$. Comparativamente à testemunha suscetível BR 601 , estes resultados significaram aumento médio de $21,7 \%$ no período préreprodutivo diminuição de $51,1 \%$ no número de descendentes e de $37,6 \%$ no peso dos insetos.

Tabela 5. Peso médio de ninfas Schizaphis graminum aos quatro e oito dias de idade, criadas em diferentes genótipos de sorgo.

\begin{tabular}{|c|c|c|}
\hline Genótipos & Peso $^{1}$ aos 4 dias (mg) & Peso $^{1}$ aos 8 dias $(\mathrm{mg})$ \\
\hline CMS x S 309 & $0,176 \mathrm{a}$ & $0,257 \mathrm{abcd}$ \\
\hline BR 007 & $0,162 a b$ & $0,273 \mathrm{abc}$ \\
\hline BR 601 & $0,133 b c$ & $0,287 \mathrm{a}$ \\
\hline 9 DX 6-27-1 & $0,131 \mathrm{bcd}$ & 0,231 bcdef \\
\hline IS $10317 \mathrm{~A}$ & 0,128 bcde & 0,190 efghi \\
\hline OK 8 B & 0,128 bcde & 0,239 abcde \\
\hline KS 9 B & 0,127 bcde & 0,234 abcde \\
\hline P 8199 & 0,123 bcde & 0,220 cdefgh \\
\hline GR & 0,121 cdef & 0,207 defghi \\
\hline $9 \mathrm{DX} 73$ & 0,117 cdef & 0,191 efghi \\
\hline S 9743 & 0,114 cdef & 0,203 defghi \\
\hline S 9750 & 0,114 cdef & 0,170 ghi \\
\hline NK Sordan & 0,113 cdef & $0,286 \mathrm{ab}$ \\
\hline IS 3422 & 0,103 cdefg & 0,226 cdefg \\
\hline KS 41 & 0,100 cdefg & $0,161 \mathrm{i}$ \\
\hline TX $430 \times($ IS $2536 \times$ SC 170) & 0,096 cdefg & 0,224 cdefg \\
\hline $\mathrm{KS} 42$ & 0,094 cdefg & 0,176 fghi \\
\hline IS $10317 \mathrm{~B}$ & 0,094 cdefg & $0,156 \mathrm{i}$ \\
\hline Н 8012 & 0,093 cdefg & 0,189 efghi \\
\hline E Redlan A & 0,092 cdefg & 0,209 defghi \\
\hline GB 3 & 0,091 cdefg & $0,163 \mathrm{i}$ \\
\hline $\mathrm{TX} 430 \times($ GR 1.1 .1$) 3.1$ & 0,090 defg & $0,163 \mathrm{i}$ \\
\hline Ranchero & 0,090 defg & 0,187 efghi \\
\hline GSBTX399xCapbam & $0,086 \mathrm{efg}$ & $0,153 \mathrm{i}$ \\
\hline TX 2567 & $0,084 \mathrm{efg}$ & $0,171 \mathrm{ghi}$ \\
\hline IS 3236 & $0,079 \mathrm{fg}$ & 0,184 efghi \\
\hline 9 DX 19 & $0,071 \mathrm{~g}$ & $0,159 \mathrm{i}$ \\
\hline IS 2293 & $0,070 \mathrm{~g}$ & $0,166 \mathrm{hi}$ \\
\hline $\mathrm{CV}(\%)$ & 3,2 & 3,1 \\
\hline
\end{tabular}

${ }^{1}$ Médias seguidas pela mesma letra na coluna não diferem significativamente, entre si, ao nível de $5 \%$ segundo o teste de Duncan. 
Portanto estes genótipos poderiam ser utilizados em programas de manejo integrado desta praga do sorgo.

\section{LITERATURA CITADA}

Berger, P.H., R.W. Toler \& K.F. Harris. 1983. Maize dwarf mosaic virus transmission by greenbug Schizaphis graminum biotypes. Plant Disease, 67: 496-497.

Cruz, I. 1986. Resistência de genótipos de sorgo ao pulgão-verde, Schizaphis graminum (Rondani, 1852) (Homoptera: Aphididae). Tese de doutorado, ESALQ/USP, Piracicaba, 222p.

Cruz, I. \& J.D. Vendramim. 1988. Efeito de diferentes níveis de infestação pelo pulgãoverde, Schizaphis graminum (Rondani, 1852) em sorgo suscetível e sorgo resistente. Pesq. Agropec. Bras. 23: 111-118.

Cruz, I. \& J.D. Vendramim. 1989a. Biologia do pulgão-verde em sorgo. Pesq. Agropec. Bras. 24: 283-289.

Cruz, I. \& J.D. Vendramim. 1989b. Não-preferência como mecanismo de resistência de sorgo ao pulgão-verde. Pesq. Agropec. Bras. 24: 329-335.

Daniels, N.E. \& R.W. Toler. 1969. Transmission of maize dwarf mosaic virus by greenbug, Schizaphis graminum. P1. Dis. Rep. 53: 59-61.

Galli, A.J.B. 1979. Resistência de Sorghum bicolor (L.) Moench a Schizaphis graminum (Rondani, 1852) (Homoptera: Aphididae): avaliação dos graus e determinação dos tipos envolvidos. Dissertação de mestrado, FCAVJ-UNESP, Jaboticabal, 52p.

Galli, A.J.B., F.M. Lara \& J.C. Barbosa. 1981. Resistência de genótipos de sorgo à Schizaphis graminum (Rondani 1852) (Homoptera: Aphididae). An. Soc. Entomol. Brasil 19: 61-71.

Gravena, S. 1978. Seletividade de inseticidas para um programa de controle integrado do pulgão-verde Schizaphis graminum (Rondani) em sorgo granífero (Sorghum bicolor L. Moench). Tese de doutorado, ESALQ/USP, Piracicaba, 182p.

Horber, H.L. 1972. Plant resistance to insects. Agric. Sci. Rev. 10: 1-18.

Kerns, D.L., D.C. Peters \& G.J. Puterka. 1987. Greenbug biotypes and greenbug resistant sorghum seed sales surveys in Oklahoma. Southwest. Entomol. 12: 237-243.

Kerns, D.L., G.J. Puterka \& D.C. Peters. 1989. Intrinsic rate of increase for greenbug (Homoptera: Aphididae) biotypes E, F, G, and $\mathrm{H}$ on small grain and sorghum varieties. Environ. Entomol. 18: 1074-1078.

Lima, A.M.C. 1942. Insetos do Brasil. Rio de Janeiro, Esc. Nac. Agron., V.3, 327p.

Lopes, S.C., J.M. Waquil \& J.A.S. Rodrigues. 1993. Identificação de biótipo de pulgão- 
verde, Schizaphis graminum (Rondani 1852) de ocorrência em Sete Lagoas, MG, p. 381. In Resumos Congresso Brasileiro de Entomologia, 14, Piracicaba, 807p.

Luginbill, P. 1969. Developing resistant plants, the ideal method of controlling insects. USDA-ARS. Prod. Res. Rep. 11: 1-14.

Painter, R.H. 1958. Resistance of plants to insects. Annu. Rev. Entomol. 3: 267-290.

Starks, K.J. \& Z.B. Mayo Jr. 1985. Biology and control of the greenbug attacking sorghum. p. 149-158. Proceeding of the International Sorghum Entomology. Workshop. Texas, USA, Texas AM. University, College Station, USA.

Teetes, G.L., D.T. Rosenow, R.D. Frederiksen \& J.W. Johnson. 1973. The predisposing influcence of greenbugs on charcoal rot of sorghum. Lubbock Country, Texas Agric. Exp. Sta. $6 \mathrm{p}$. 